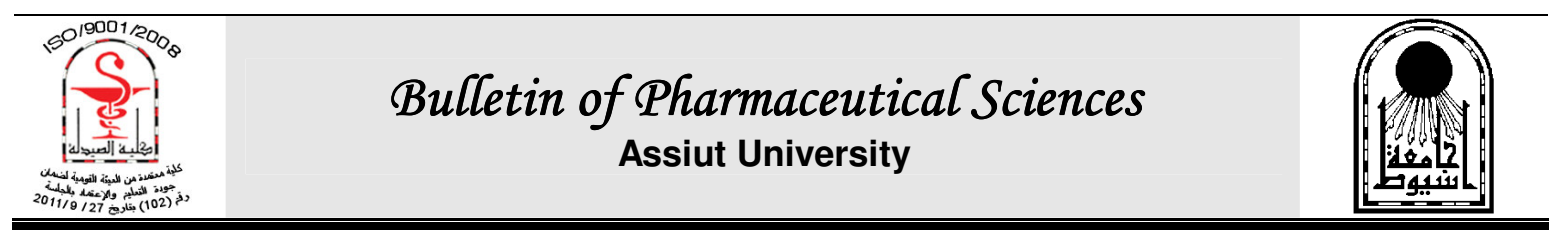

\title{
FORMULATION AND EVALUATION OF A COLON DRUG DELIVERY SYSTEM CONTAINING DIFLUNISAL
}

\author{
E. E. Zein El Din", G. M. El Maghraby, A. A. Donia and S. I. Mayah \\ Department of Pharmaceutical Technology, Faculty of pharmacy, Tanta university, Tanta, \\ Egypt
}

\begin{abstract}
Oral drug delivery is the most desirable and preferred method of administering therapeutic agents for providing both systemic and local effects in various parts of the gastrointestinal tract. Recently, greater emphasis has been placed on controlling the site and/or rate of drug release from oral formulations to improve treatment efficacy and patient compliance. Many novel oral drug therapeutic systems have been invented like fast release, targeted release and colon specific drug delivery systems etc.. During the last decade there has been an interest in developing site specific formulations for targeting to the colon. The delivery of drugs to the colon has a number of therapeutic implications in the field of drug delivery. Localized delivery of the drugs in the colon is possible only when the drug is protected from the hostile environment of upper GIT. The various approaches that can be exploited to target the release of drug to colon include prodrugs, coating with $\mathrm{pH}$ sensitive polymers, coating with biodegradable, timed release systems, osmotic and bioadhesive polymers.

In the present study, solid dispersions of $\mathrm{pH}$-dependent, time dependent and combined $\mathrm{pH}$ and time-dependent systems were formulated using Eudragit RS100, Eudragit S100, Eudragit L100 and ethylcellulose, with different drug-to-polymer ratios. They were evaluated for their in-vitro release characteristics in an attempt to develop a colon-specific delivery system containing Diflunisal. Release studies of Diflunisal and Diflunisal solid dispersion systems with different polymers were employed using Release apparatus, USP (paddle type) (copley, England) showed that, the combination of $\mathrm{pH}$ - and time-dependent systems provided better results than the $\mathrm{pH}$-dependent or the time dependent system alone. Using Eudragit S100 and Eudragit RS100 with Diflunisalin a ratio 2:3:1, respectively for preparing a solid dispersion used for developing a colon-specific delivery system of Diflunisal was the most successful formula. This formula released $0.22 \pm 0.03 \%$ of the drug included in it in the stomach $\mathrm{pH}$ and $26.29 \pm 0.91 \%$ of the drug in the intestine $\mathrm{pH}$ and $77.59 \pm 1.79 \%$ of the drug in the colon $\mathrm{pH}$.
\end{abstract}

\section{INTRODUCTION}

Drug delivery technologies modify drug release profile, absorption, distribution and elimination for improving product efficacy and safety, as well as patient convenience and compliance $^{1}$. Most common routes of administration include the preferred noninvasive peroral, topical, nasal, buccal/sublingual, vaginal, ocular, rectal and inhalation routes ${ }^{2}$.

The oral route is considered as the most convenient one for administration of drugs. Drug normally dissolves in gastric and

Received in 8/2/2014 \& Accepted in 22/3/2014

*Corresponding author: E. E. Zein El Din, E-mail: Dr.esmat.zein@gmail.com intestinal fluids and then absorbed from these regions. It is a serious drawback in conditions when localized delivery of drugs into the colon is required as these drugs need to be protected from the hostile environment of upper $\mathrm{GIT}^{3}$.

Targeted drug delivery into the colon is highly desirable for local treatment of variety of bowl diseases such as ulcerative colitis, cirrhosis disease, amoebiasis, colonic cancer. In addition for using the column for local affect, it may be used also for systemic delivery of some drugs like insulin, calcitonin and vasopressin ${ }^{4}$. The colon may be also used for the delivery of drugs, which are polar and / or 
susceptible to chemical and enzymatic degradation in upper GIT $^{5}$ and for drugs which are highly affected by hepatic metabolism ${ }^{6}$.

There are two approaches for colonic drug delivery. The first is by making covalent linkage of drug with carrier like azo bond, glycoside, glucuronide, cyclodextrin, dextran and amino-acid conjugates ${ }^{7}$. The second approache is by delivering the intact drug molecule to the colon by many ways like embedding in $\mathrm{pH}$-sensitive matrices, time dependent delivery, bioadhesive systems, pressure controlled system, osmotic controlled drug delivery and polysaccharide based delivery systems ${ }^{8}$.

One of the most effective approaches is by using the $\mathrm{pH}$ dependent polymers. This approach utilizes the existence of $\mathrm{pH}$ gradient in the gut that increases progressively from the stomach $(\mathrm{pH} 1.5-3.5)$ to the small intestine (5.5-6.8) and finally to the colon (6.4-7.0) ${ }^{9}$.

The polymers used for colon targeting, however, should be able to withstand the lower $\mathrm{pH}$ values of the stomach and of the proximal part of the small intestine and also be able to disintegrate at the neutral or slightly alkaline $\mathrm{pH}$ of the terminal ileum and preferably at the ileocecal junction. The problem with this approach is that the intestinal $\mathrm{pH}$ may vary because it is affected by diet, disease, presence of fatty acids and other fermentation products. Moreover, there is a considerable difference in inter- and intraindividual gastrointestinal tract $\mathrm{pH}$, and this causes a major problem in reproducible drug delivery to the large intestine $^{10}$. The most commonly used $\mathrm{pH}$ dependent polymers are derivatives of acrylic acid and cellulose $\mathrm{e}^{11}$.

Using non steroidalanti inflammatory drugs for treating colon diseases is the best medical of choice. Diflunisal is a promising drug for treating colon ulcers but there are no studies confirm that ${ }^{12}$. Diflunisal acts by inhibiting the cyclo-oxygenase (COX)mediated production of prostaglandins ${ }^{13}$.

The aim of the present work is to prepare solid dispersions containing Diflunisal using different types of polymers, development of a suitable analytical technique for quantification of the drug and in-vitro evaluation of the prepared solid dispersions that would be used for developing a colonic drug delivery system for local delivery of Diflunisal.

\section{MATERIALS AND METHODS}

\section{Materials}

Diflunisal, Eudragit S100, Eudragit RS100, Eudragit L100 and ethylcellulose were obtained as a gift from Sigma-Aldrich (st. Louis, MO, USA). Disodium hydrogen phosphate, hydrochloric acid and sodium hydroxide pellets were obtained from RiedeldeHaen (Seelze, Germany). All other solvents and reagents were of analytical grade and used as received.

\section{Preparation of solid dispersion}

Solid dispersions containing Diflunisal were prepared by solvent evaporation technique $^{14}$, Eudragit S100, Eudragit RS100, Eudragit L100 and ethylcellulose were used and a mixture of ethanol and dichloromethane in 1:1 ratio was used as a common solvent for the drug and the polymer in the present study.

\section{Method of preparation}

Six hundred milligrams of Diflunisal were accurately weighed and dissolved in $100 \mathrm{ml}$ of the solvent mixture. The calculated amounts of the polymer(s) according to the proposed formula were weighed and dissolved in $150 \mathrm{ml}$ of the same solvent mixture at $40^{\circ} \mathrm{C}$. The polymer solution was added gradually to the drug solution with continuous stirring using a magnetic stirrer (Maxi mix 11, Thermolyne Corporation, U.S.A.), then warmed over a water-bath at $40^{\circ} \mathrm{C}$ until the total volume was reduced to about $20 \mathrm{ml}$. The rest of the solvent was allowed to evaporate at room temperature in a porcelain dish till a dry film was obtained. The dry film formed was pulverized in a porcelain mortar and sieved through a sieve no. 450 in order to obtain granules with homogenous particle size. Each formulation was appropriately labeled and stored in a dessicator for release and further studies.

The composition of the prepared solid dispersions is illustrated in table 1 . 
Table 1: Composition of solid dispersions containing Diflunisal using different polymers.

\begin{tabular}{|c|c|c|c|c|c||}
\hline Formula & Diflunisal & $\begin{array}{c}\text { Eudragit } \\
\text { L100 }\end{array}$ & $\begin{array}{c}\text { Eudragit } \\
\text { S100 }\end{array}$ & $\begin{array}{c}\text { Eudragit } \\
\text { RS100 }\end{array}$ & $\begin{array}{c}\text { Ethyl- } \\
\text { cellulose }\end{array}$ \\
\hline F1 & 1 & 1 & - & - & - \\
\hline F2 & 1 & 3 & - & - & - \\
\hline F3 & 1 & 5 & - & - & - \\
\hline F4 & 1 & - & - & 1 & - \\
\hline F5 & 1 & - & - & 2 & - \\
\hline F6 & 1 & - & 1 & - & - \\
\hline F7 & 1 & - & 3 & - & - \\
\hline F8 & 1 & - & 5 & - & - \\
\hline F9 & 1 & - & 3 & - & 0.5 \\
\hline F10 & 1 & - & 3 & - & 1 \\
\hline F11 & 1 & - & 3 & 2 & - \\
\hline F12 & 1 & - & 1 & 1 & - \\
\hline F13 & 1 & - & 1 & 2 & - \\
\hline F14 & 1 & - & 0.5 & 1.5 & - \\
\hline F15 & 1 & - & 1 & 1.5 & - \\
\hline
\end{tabular}

\section{Determination of diflunisal content in the prepared solid dispersions}

An accurately weighed amount of each formulation equivalent to $25 \mathrm{mg}$ Diflunisal was dissolved with $50 \mathrm{ml}$ of a solvent mixture of ethanol and dicloro methane at $1: 1$ ratio. $1 \mathrm{ml}$ from this stock solution was transferred to 50 $\mathrm{ml}$ volumetric flask, then the volume was completed to $50 \mathrm{ml}$ with ethanol. Diflunisal content was determined spectrophotometrically at $255 \mathrm{~nm}$ (Shimadzu (UV- 160A) Japan). against ethanol as a blank with reference to standard curve.

The following equation was employed for calculation of drug entrapment efficiency ${ }^{15}$ :

Entrapment efficiency=

(Drug entrapped/Theoretical drug content)*100.

Experiments were performed in triplicates and the average readings were reported $( \pm \mathrm{SD})$.

\section{In-vitro drug release studies}

Release experiments were conducted on the binary and ternary formulations. The tests employed the USP XXIV method 2 (paddle type) release apparatus (Electro lab TDT-06P, India). The release medium was $500 \mathrm{ml} 0.1 \mathrm{~N}$ $\mathrm{HCl}(\mathrm{pH} 1.2)$ maintained at a temperature of $37 \pm 0.5^{\circ} \mathrm{C}$ with a stirring rate of $50 \mathrm{rpm}$.
$5 \mathrm{ml}$ Samples were withdrawn at predetermined time intervals of 5, 15, 30, 60, 90 and $120 \mathrm{~min}$., respectively. Fresh release medium was added to replenish for each sample. The samples were filtered through 0.45 $\mu \mathrm{m}$ filter (millipore filter) and the filtrate was analyzed for drug content using spectrophotometric method. After the last sample ( $2 \mathrm{hrs})$, the $\mathrm{pH}$ of the release medium was adjusted to 6.8 to simulate the intestinal $\mathrm{pH}$ (USP 24). This was achieved by addition of $200 \mathrm{ml}$ of $0.3 \mathrm{M}$ dibasic sodium phosphate and $25 \mathrm{ml}$ of $1 \mathrm{~N}$ sodium hydroxide. Sampling was then continued for another $4 \mathrm{hrs}$ at the end of which the medium was adjusted to 7.4 using 1 $\mathrm{N}$ sodium hydroxide and sampling was continued for another $4 \mathrm{hrs}$. The withdrawn samples were treated as above. Experiments were performed in triplicates and the average readings were reported $( \pm \mathrm{SD})$.

\section{RESULTS AND DISCUSSION}

\section{Diflunisal content}

Drug content in the selected formula is illustrated in table 2.

From the table, it is clear that the percent of Diflunisal content in all prepared formulations ranged between $95 \%$ and $105 \%$, which indicates that the selected method for preparation of solid dispersions was appropriate and convenient. 
Table 2: Percentage of drug content in the selected formulations.

\begin{tabular}{|c|c|c|c||}
\hline Formula & Diflunisal content $\% \pm$ S.D. & Formula & Diflunisal content $\% \pm$ S.D. \\
\hline F1 & $99.102 \pm 4.211$ & F9 & $98.534 \pm 2.675$ \\
\hline F2 & $99.204 \pm 2.361$ & F10 & $100.00 \pm 3.687$ \\
\hline F3 & $102.678 \pm 1.928$ & F11 & $98.012 \pm 1.907$ \\
\hline F4 & $99.428 \pm 3.519$ & F12 & $99.044 \pm 2.281$ \\
\hline F5 & $96.911 \pm 4.030$ & F13 & $99.832 \pm 2.248$ \\
\hline F6 & $101.165 \pm 2.237$ & F14 & $98.117 \pm 2.374$ \\
\hline F7 & $99.133 \pm 1.349$ & F15 & $102.022 \pm 1.023$ \\
\hline F8 & $99.945 \pm 4.841$ & & \\
\hline
\end{tabular}

\section{Release studies}

Great attention has been devoted to the use of oral-delivery systems containing acrylic polymers, since these polymers are essentially insoluble in the gastric juice and may be used to impart enteric behavior to the encapsulated drug serving as a drug target device to the colon $^{16-18}$. It is known that these polymers are sensitive to $\mathrm{pH}$ changes and are able to protect the drug from the release in the gastric fluid, which is very acid $(\mathrm{pH}=1-2)^{19 \& 20}$.

Eudragit is a reversibly soluble polymer depending on $\mathrm{pH}^{21}$ so it can promote a controlled delivery of drug in specific colonic diseases $^{22}$.In fact an enteric copolymer should have in its structure a hydrophilic monomeric unit, such as that of the methacrylic acid one, and another hydrophobic one, such as the methyl methacrylate. The behavior of this material is dependent on protonation state, at higher $\mathrm{pH}$, the carboxylic groups became ionized, changing their conformations and expanding them due to the repulsion between the negative charges of the carboxylates. At lower $\mathrm{pH}$ the carboxylic groups are unionized. The conformations are so closed allowing that the copolymer can precipitate. This process is mimicking the $\mathrm{pH}$ change that accounts all over the gastro-intestinal tract ${ }^{23}$.

In the present study Eudragit S100, Eudragit L100, Eudragit RS100 and ethylcellulose were used in order to delay the release of Diflunisal until reaching the colon.
Eudragit L100 is a $\mathrm{pH}$ dependent polymer which was used by Zahirul et $a .^{24}$ for colontargeted delivery of mesalazine, but they found that eudragit L100 can't protect the drug until it reaches the colon. The authers found that addition Eudragit S100 to the solid dispersion of the drug and Eudragit L100 can solve this problem. Asghar and Chandran ${ }^{25}$ found the same results with indomethacin. Solid dispersion of Eudragit L100 alone with the drug can't reach the colon. It released completely in the intestine.

The obtained results were in agreement with the previous studies, Eudragit L100 can't protect Diflunisal until it reaches the colon. The release results of the solid dispersions F1, F2 and F3 which have 1:1, 1:3 and 1:5 drug to polymer ratio respectively, are illustrated in table 3 and figure 1.

From table 3 and figure 1 it is clear that, at $\mathrm{pH} 1.2$, the $\%$ of the amounts of the drug released after $120 \mathrm{~min}$ were $0.46 \pm 0.11$, $0.42 \pm 0.02$ and $0.42 \pm 0.08 \%$ from F1, F2 and F3 solid dispersions, respectively. It is clear that upon increasing the polymer ratio, the amount released was decreased. This may be due to the increase in the coat thickness. At $\mathrm{pH}$ 1.2, Eudragit L100 solid dispersions at different polymer ratios cause a significant reduction in the amount released of Diflunisal within 120 $\mathrm{min}$. The release efficiencies (\%DE) of F1, F2 and F3 solid dispersions were $0.35 \pm 0.01$, $0.33 \pm 0.04$ and $0.32 \pm 0.02 \%$ respectively. 
Table 3: Cumulative amount of Diflunisal released from Diflunisal : Eudragit L100 solid dispersions at various $\mathrm{pH}$ values.

\begin{tabular}{|c|c|c|c|c|c||}
\hline \multirow{2}{*}{$\begin{array}{c}\text { Time } \\
(\mathrm{min})\end{array}$} & \multirow{2}{*}{$\mathrm{pH}$} & \multicolumn{4}{|c|}{ Cumulative amount of Diflunisal released $(\%) \pm$ S.D. } \\
\cline { 3 - 5 } & & $\mathrm{F} 1$ & $\mathrm{~F} 2$ & $\mathrm{~F} 3$ & \multirow{2}{*}{ Free drug } \\
\cline { 3 - 6 } & & $\mathrm{D}: \mathrm{P}$ & $\mathrm{D}: \mathrm{P}$ & $\begin{array}{c}\mathrm{D}: \mathrm{P} \\
1: 3\end{array}$ & \\
\hline 15 & 1.2 & $0.27 \pm 0.07$ & $0.24 \pm 0.03$ & $0.23 \pm 0.01$ & $2.45 \pm 0.002$ \\
\hline 30 & 1.2 & $0.31 \pm 0.01$ & $0.29 \pm 0.02$ & $0.27 \pm 0.03$ & $2.71 \pm 0.001$ \\
\hline 60 & 1.2 & $0.33 \pm 0.02$ & $0.31 \pm 0.05$ & $0.29 \pm 0.07$ & $3.04 \pm 0.004$ \\
\hline 90 & 1.2 & $0.40 \pm 0.09$ & $0.38 \pm 0.02$ & $0.37 \pm 0.04$ & $3.61 \pm 0.007$ \\
\hline 120 & 1.2 & $0.46 \pm 0.11$ & $0.42 \pm 0.02$ & $0.42 \pm 0.08$ & $4.34 \pm 0.004$ \\
\hline 135 & 6.8 & $44.79 \pm 1.13$ & $38.95 \pm 0.91$ & $26.65 \pm 0.75$ & $91.51 \pm 0.71$ \\
\hline 150 & 6.8 & $83.69 \pm 1.02$ & $89.97 \pm 0.95$ & $55.32 \pm 1.18$ & $100.00 \pm 0.52$ \\
\hline 180 & 6.8 & $100.00 \pm 0.73$ & $99.18 \pm 0.45$ & $87.22 \pm 1.76$ & \\
\hline 210 & 6.8 & & $100.00 \pm 0.57$ & $100.00 \pm 0.78$ & \\
\hline
\end{tabular}

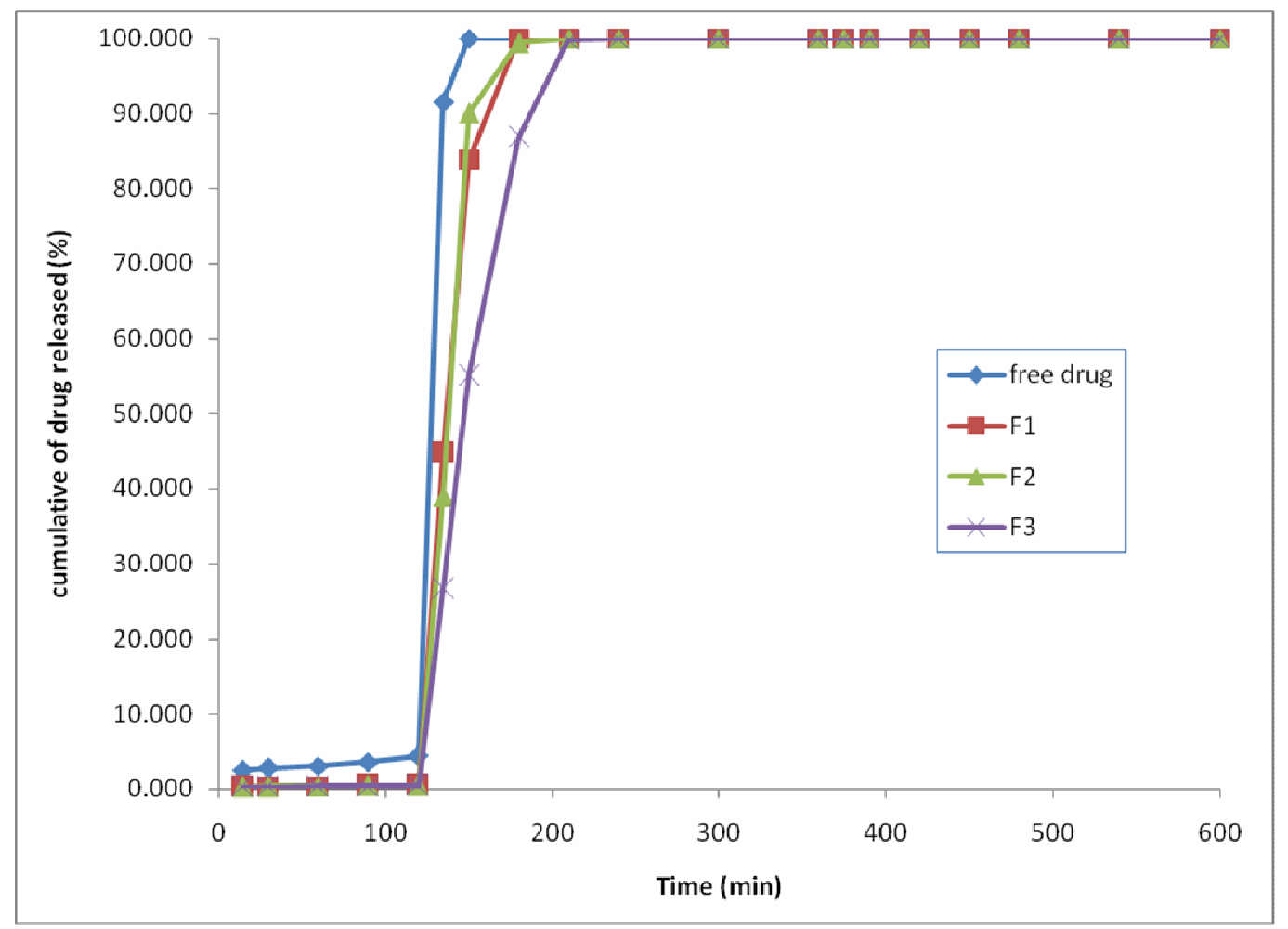

Fig. 1: Cumulative amount of Diflunisal released from Diflunisal : Eudragit L100 solid dispersions at various $\mathrm{pH}$ values. 
At $\mathrm{pH} 6.8$, the $\%$ of the amounts of the drug released after $210 \mathrm{~min}$ were $100 \%$ for $\mathrm{F} 1$, F2 and F3 solid dispersions, so that Eudragit L100 can't protect the drug in its matrix until it reaches the colon as it dissolves completely at pH 6.8 which is lower than that of the colon ${ }^{26}$. The release efficiencies (\%DE) of F1, F2 and F3 solid dispersions were 94.86 \pm 0.27 , $94.96 \pm 0.11$ and $89.24 \pm 0.09 \%$ respectively.

Eudragit RS100 is a time dependent polymer which was used by Pignatello $e t a l .^{27}$ and Pignatello et al. ${ }^{28}$ in a solid dispersion with Diflunisal in order to get a sustained release formula.

The findings of the present study complied with the previous studies. Formula 4 and F5 solid dispersions contained $1: 1$ and 1:2 drug to polymer ratio. Formula 4 can't protect the drug until it reach the colon. All the drug was released in the intestine. Formula 5 can protect the drug until it reaches the colon but it can't release all the drug in the colon. Drug release results from F4 and F5 are illustrated in table 4 and figure 2 .

From table 4 and figure 2 it is clear that, at $\mathrm{pH} \mathrm{1.2,} \mathrm{the} \mathrm{\%} \mathrm{of} \mathrm{the} \mathrm{amounts} \mathrm{of} \mathrm{the} \mathrm{drug}$ released after $120 \mathrm{~min}$ were $0.36 \pm 0.03$ and $0.26 \pm 0.02$ from F4 and F5 solid dispersions, respectively. It is clear that upon increasing the polymer ratio in the formula, the percentage released decreased, this may be due to the increase in coating efficiency. All Eudragit RS100 solid dispersions at different polymer ratios cause a significant reduction in the percentage of Diflunisal released after $120 \mathrm{~min}$ as compared to the free drug. The release efficiencies of F4 and F5 solid dispersions were $0.25 \pm 0.05$ and $0.17 \pm 0.07 \%$ respectively.

Table 4: Cumulative amount of Diflunisal released from Diflunisal : Eudragit RS100 solid dispersions at various $\mathrm{pH}$ values.

\begin{tabular}{|c|c|c|c|}
\hline \multirow{3}{*}{$\begin{array}{l}\text { Time } \\
(\min )\end{array}$} & \multirow{3}{*}{$\mathrm{pH}$} & \multicolumn{2}{|c|}{$\begin{array}{c}\text { Cumulative amount of Diflunisal released (\%) } \\
\pm \text { S.D. }\end{array}$} \\
\hline & & F4 & F5 \\
\hline & & $\begin{array}{l}\mathrm{D}: \mathrm{P} \\
1: 1\end{array}$ & $\begin{array}{l}\mathrm{D}: \mathrm{p} \\
1: 2\end{array}$ \\
\hline 15 & 1.2 & $0.18 \pm 0.01$ & $0.09 \pm 0.00$ \\
\hline 30 & 1.2 & $0.21 \pm 0.03$ & $0.12 \pm 0.02$ \\
\hline 60 & 1.2 & $0.24 \pm 0.01$ & $0.14 \pm 0.02$ \\
\hline 90 & 1.2 & $0.27 \pm 0.02$ & $0.22 \pm 0.01$ \\
\hline 120 & 1.2 & $0.36 \pm 0.03$ & $0.26 \pm 0.02$ \\
\hline 135 & 6.8 & $60.08 \pm 0.98$ & $8.35 \pm 0.71$ \\
\hline 150 & 6.8 & $71.76 \pm 1.16$ & $10.42 \pm 0.88$ \\
\hline 180 & 6.8 & $82.02 \pm 1.68$ & $15.01 \pm 0.96$ \\
\hline 210 & 6.8 & $92.22 \pm 1.94$ & $22.11 \pm 1.03$ \\
\hline 240 & 6.8 & $100.00 \pm 0.42$ & $26.04 \pm 1.08$ \\
\hline 300 & 6.8 & & $30.12 \pm 1.14$ \\
\hline 360 & 6.8 & & $32.00 \pm 1.09$ \\
\hline 375 & 7.4 & & $38.13 \pm 1.11$ \\
\hline 390 & 7.4 & & $39.17 \pm 1.07$ \\
\hline 420 & 7.4 & & $39.25 \pm 0.75$ \\
\hline 450 & 7.4 & & $41.04 \pm 0.22$ \\
\hline 480 & 7.4 & & $42.00 \pm 0.56$ \\
\hline 540 & 7.4 & & $44.12 \pm 1.17$ \\
\hline 600 & 7.4 & & $46.23 \pm 1.23$ \\
\hline
\end{tabular}




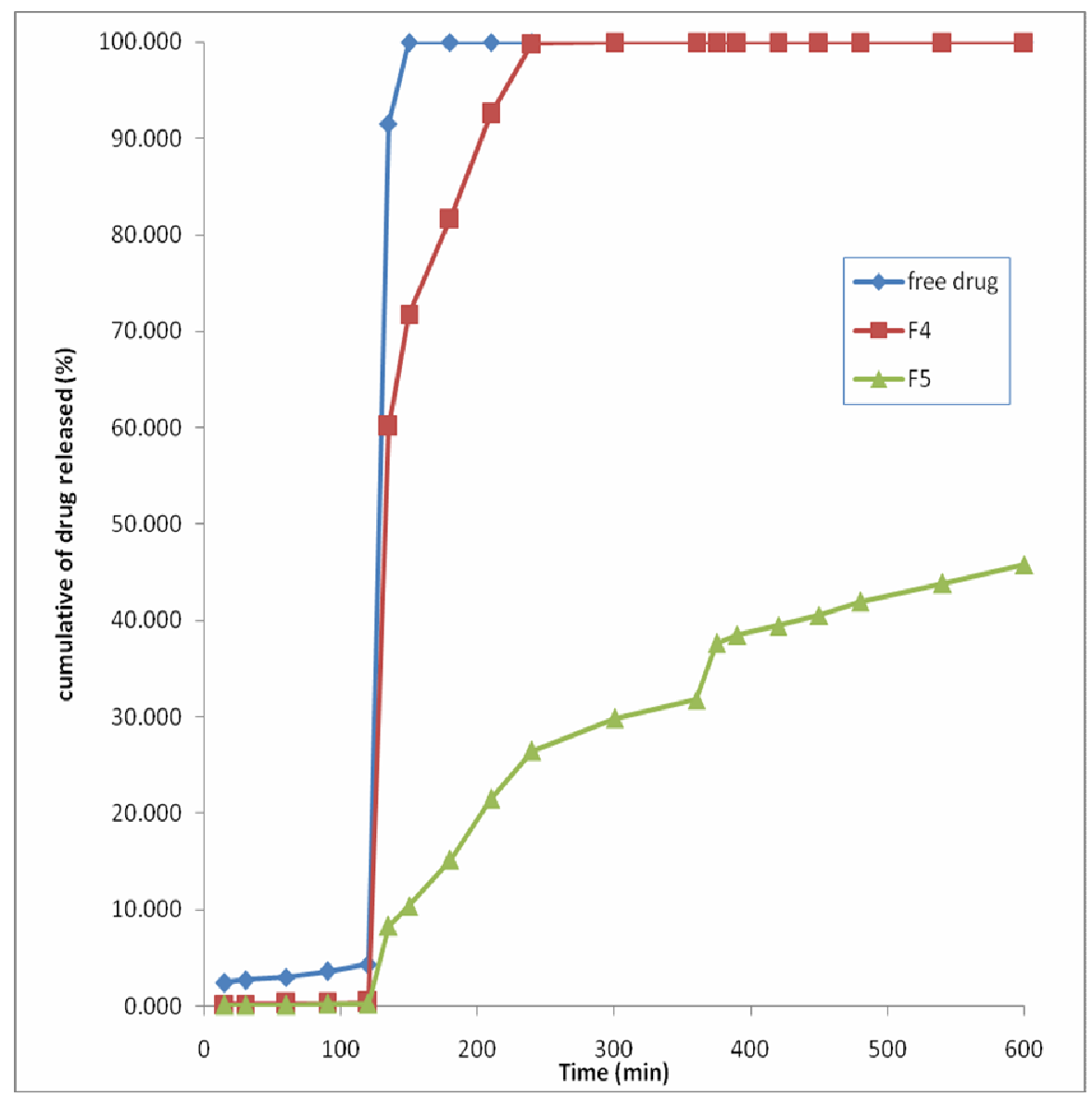

Fig. 2: Cumulative amount of Diflunisal released from Diflunisal : Eudragit RS100 solid dispersions at various $\mathrm{pH}$ values.

At $\mathrm{pH} 6.8$ the $\%$ of the amounts of the drug released after $240 \mathrm{~min}$ were 100 and $32 \pm 1.09 \%$ from $\mathrm{F} 4$ and F5 solid dispersions, respectively. The release efficiencies of F4 and F5 solid dispersions were $91.34 \pm 0.24$ and $23.22 \pm 0.14 \%$ respectively.

At $\mathrm{pH} 7.4$ the $\%$ of the amount of the drug released after $240 \mathrm{~min}$ was $46.23 \pm 1.23 \%$ from F5. The release efficiencies of F4 and F5 solid dispersions were $100.00 \pm 0.17$ and $41.97 \pm 0.26 \%$ respectively.

Eudragit $\mathrm{S} 100$ is a $\mathrm{pH}$ dependent polymer which was used for many purposes. Khan et. $a l .^{29}$, used Eudragit S100 solid dispersion with mesalazine for delaying its release until it reaches the colon but combining it with Eudragit L100-55 might give much better results. Kadam and Gattani ${ }^{30}$ used Eudragit S100 with theophylline for developing tablets for pulsatile drug delivery system but also it couldn't give good results until it was combined with Eudragit RL100.

Similar results were noticed in the present study. Eudragit S100 solid dispersions with a certain ratios (1:3 and 1:5 drug to polymer ratio respectively) could delay release of Diflunisal until it reaches the colon, but it couldn't give the required results when it was alone. The release results of the solid dispersions F4, F5 and F6 which contain 1:1, 1:3 and 1:5 drug to polymer ratio respectively which are illustrated in table 5 and figure 3.

From table 5 and figure 3 it is clear that, at $\mathrm{pH} 1.2$, the \% of the amounts of the drug released after $120 \mathrm{~min}$ were $0.39 \pm 0.03$, $0.29 \pm 0.01$ and $0.231 \pm 0.02 \%$ from F6, F7 and F8 solid dispersion, respectively. It is clear that upon increasing the polymer ratio at $\mathrm{pH}$ 1.2, different types of Eudragit S100 solid dispersions at different polymer ratios cause a 
significant reduction in the percentage released of Diflunisal after $120 \mathrm{~min}$. The release efficiencies of F6, F7 and F8 solid dispersions were $0.15 \pm 0.03,0.19 \pm 0.06$ and $0.15 \pm 0.04 \%$ respectively.

At $\mathrm{pH} 6.8$, the \% of the amounts of the drug released after 240 min were $100.00 \pm 0.54$, $63.12 \pm 0.63$ and $27.22 \pm 0.45 \%$ from F6, F7 and F8 solid dispersions, respectively. Presence of Diflunisal with Eudragit S100 in a solid dispersion form caused a significant decrease in the percentage released after $240 \mathrm{~min}$ as compared with the free drug. The release efficiencies of F6, F7 and F8 solid dispersions were $73.67 \pm 0.08,48.56 \pm 0.15$ and $16.86 \pm 0.31 \%$ respectively.
At $\mathrm{pH} 7.4$, the $\%$ of the amounts released after $240 \mathrm{~min}$ were $94.19 \pm 0.53$ and $53.42 \pm 0.59 \%$ from F7 and F8, respectively. In case of F7 and F8, not all the drug included in the two solid dispersions was released after 10 hrs of release at different $\mathrm{pH}$ values from 1.2 to 7.4. This may be due to the fact that the release of the drug from the polymer matrix takes place after complete swelling of the polymer and as the amount of polymer in the formulation increases the time required to swell also increases $^{31}$. The release efficiencies of $\mathrm{F} 6, \mathrm{~F} 7$ and F8 solid dispersions were $100.00 \pm 0.13$, $84.26 \pm 0.25$ and $45.00 \pm 0.22 \%$ respectively.

Table 5: Cumulative amount of Diflunisal released from Diflunisal : Eudragit S100 solid dispersions at various $\mathrm{pH}$ values.

\begin{tabular}{|c|c|c|c|c||}
\hline \multirow{2}{*}{$\begin{array}{c}\text { Time } \\
\text { (min) }\end{array}$} & \multirow{2}{*}{$\mathrm{pH}$} & \multicolumn{3}{|c|}{ Cumulative amount of Diflunisal released $(\%) \pm$ S.D. } \\
\cline { 3 - 5 } & & $\mathrm{F} 6$ & $\mathrm{~F} 7$ & $\mathrm{~F} 8$ \\
\cline { 3 - 5 } & & $\mathrm{D}: \mathrm{P}$ & $\mathrm{D}: \mathrm{P}$ & $\mathrm{D}: \mathrm{P}$ \\
& $1: 1$ & $1: 3$ & $1: 5$ \\
\hline 15 & 1.2 & $0.20 \pm 0.02$ & $0.12 \pm 0.01$ & $0.075 \pm 0.04$ \\
\hline 30 & 1.2 & $0.26 \pm 0.00$ & $0.14 \pm 0.02$ & $0.112 \pm 0.01$ \\
\hline 60 & 1.2 & $0.27 \pm 0.04$ & $0.18 \pm 0.01$ & $0.127 \pm 0.03$ \\
\hline 90 & 1.2 & $0.30 \pm 0.01$ & $0.23 \pm 0.03$ & $0.195 \pm 0.01$ \\
\hline 120 & 1.2 & $0.39 \pm 0.03$ & $0.29 \pm 0.01$ & $0.231 \pm 0.02$ \\
\hline 135 & 6.8 & $15.75 \pm 0.37$ & $23.47 \pm 0.25$ & $6.259 \pm 0.11$ \\
\hline 150 & 6.8 & $28.11 \pm 0.12$ & $27.52 \pm 0.16$ & $6.753 \pm 0.13$ \\
\hline 180 & 6.8 & $59.05 \pm 0.34$ & $44.03 \pm 0.29$ & $10 \pm 0.24$ \\
\hline 210 & 6.8 & $70.00 \pm 0.39$ & $51.05 \pm 0.13$ & $14 \pm 0.36$ \\
\hline 240 & 6.8 & $82.31 \pm 0.18$ & $52.00 \pm 0.47$ & $17 \pm 0.46$ \\
\hline 300 & 6.8 & $95.06 \pm 0.27$ & $54.23 \pm 0.32$ & $23 \pm 0.39$ \\
\hline 360 & 6.8 & $100.00 \pm 0.54$ & $63.12 \pm 0.63$ & $27.22 \pm 0.45$ \\
\hline 375 & 7.4 & & $70.37 \pm 0.57$ & $38 \pm 0.31$ \\
\hline 390 & 7.4 & & $74.51 \pm 0.46$ & $39 \pm 0.29$ \\
\hline 420 & 7.4 & & $78.21 \pm 0.25$ & $41 \pm 0.52$ \\
\hline 450 & 7.4 & & $83.54 \pm 0.72$ & $43 \pm 0.37$ \\
\hline 480 & 7.4 & & $85.81 \pm 0.54$ & $45 \pm 0.17$ \\
\hline 540 & 7.4 & & $90.07 \pm 0.61$ & $48 \pm 0.22$ \\
\hline 600 & 7.4 & & $94.19 \pm 0.53$ & $53.42 \pm 0.59$ \\
\hline
\end{tabular}




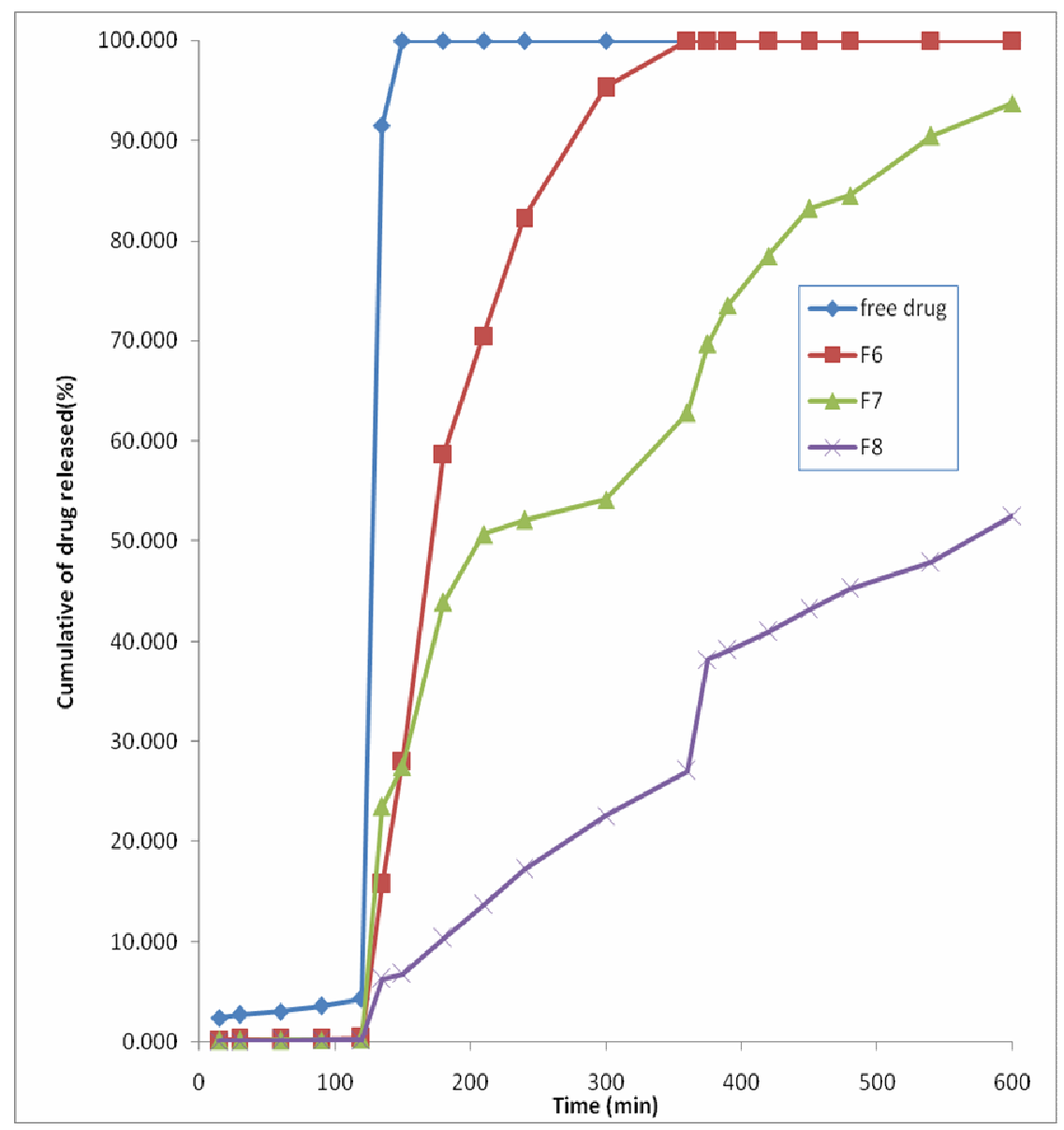

Fig. 3: Cumulative amount of Diflunisal released from Diflunisal : Eudragit S100 solid dispersions at various $\mathrm{pH}$ values.

Combining two systems like $\mathrm{pH}$ dependent system and time dependent system for controlling the release of a drug was found to be more efficient than using one of the polymers alone. Gowda et al. ${ }^{32}$ used a solid dispersion containing ethylcellulose as a time dependent polymer and Eudragit $\mathrm{S} 100$ as a $\mathrm{pH}$ dependent polymer for minimizing the unwanted toxic effects of anti-anginal ranolazine by kinetic control of drug release. The same combination was used with Diflunisal in the present study for delivering it to the colon.

The release results of the solid dispersions F6, F7 and F8, which contain 1:3:0.5 and 1:3:1 drug to Eudragit S100 to ethylcellulose ratio respectively, are illustrated in table 6 and figure 4.

From table 6 and figure 4 it is clear that, at $\mathrm{pH} 1.2$, the \% of the amound of drug released after $120 \mathrm{~min}$ were $0.319 \pm 0.002$ and
$0.352 \pm 0.004 \%$ from F9 and F10, respectively. It is clear that, upon increasing the ratio of ethylcellulose, the percentage released after $120 \mathrm{~min}$ at $\mathrm{pH} 1.2$ was more than the that released from solid dispersions of Eudragit S100 only. The release efficiencies of F9 and F10 solid dispersions were $0.21 \pm 0.05$ and $0.23 \pm 0.10 \%$ respectively.

At $\mathrm{pH} 6.8$, the $\%$ of the amounts of the drug released after $240 \mathrm{~min}$ were $65.270 \pm 0.27$ and $71.870 \pm 0.42 \%$ from F9 and F10, respectively. The release efficiencies of F9 and F10 solid dispersions were 46.46 \pm 0.16 and $55.78 \pm 0.28 \%$ respectively.

At $\mathrm{pH} 7.4$, all the $\%$ of the amount of Diflunisal that was still included in the solid dispersion, was released completely from both $\mathrm{F} 9$ and F10. The release efficiencies of F9 and F10 solid dispersions were $95.34 \pm 0.34$ and $97.37 \pm 0.12 \%$ respectively. 
F9 and F10 solid dispersions didn't match with the requirements of the colonic delivery as they released $65.270 \pm 0.27$ and $71.870 \pm 0.42 \%$ respectively of the drug in the intestine. Few amount of the drug could reach the colon.

Another combination of time dependent and $\mathrm{pH}$ dependent systems was studied by Akhgari et al. ${ }^{13}$. They evaluate the combination of $\mathrm{pH}$-dependent and time-dependent polymers for design of colon delivery system of indomethacin pellets. Eudragit S100 and Eudragit L100 were used as $\mathrm{pH}$-dependent polymers and Eudragit RS100 was used as a time-dependent polymer.

In the present study combining Eudragit S100 and Eudragit RS100 was sufficient to obtain a successful colon drug delivery system. Many preparations with different drug to polymer ratios were studied in order to obtain a suitable formula.

Table 6: Cumulative amount of Diflunisal released from Diflunisal : Eudragit S100 : Ethylcellulose dispersions at various $\mathrm{pH}$ values.

\begin{tabular}{|c|c|c|c|}
\hline \multirow{3}{*}{$\begin{array}{l}\text { Time } \\
(\min )\end{array}$} & \multirow{3}{*}{$\mathrm{pH}$} & \multicolumn{2}{|c|}{ Cumulative amount of Diflunisal released $(\%) \pm$ S.D. } \\
\hline & & F9 & F10 \\
\hline & & $\begin{array}{c}\text { Drug : Eud S100 : E.C. } \\
1: 3: 0.5\end{array}$ & $\begin{array}{c}\text { Drug : Eud S100 : E.C. } \\
1: 3: 1\end{array}$ \\
\hline 15 & 1.2 & $0.12 \pm 0.01$ & $0.17 \pm 0.02$ \\
\hline 30 & 1.2 & $0.17 \pm 0.03$ & $0.19 \pm 0.01$ \\
\hline 60 & 1.2 & $0.21 \pm 0.01$ & $0.22 \pm 0.05$ \\
\hline 90 & 1.2 & $0.24 \pm 0.04$ & $0.26 \pm 0.03$ \\
\hline 120 & 1.2 & $0.32 \pm 0.02$ & $0.35 \pm 0.04$ \\
\hline 135 & 6.8 & $20.11 \pm 0.22$ & $33.68 \pm 0.11$ \\
\hline 150 & 6.8 & $24.18 \pm 0.27$ & $37.02 \pm 0.23$ \\
\hline 180 & 6.8 & $36.26 \pm 0.56$ & $40.48 \pm 0.33$ \\
\hline 210 & 6.8 & $42.09 \pm 0.32$ & $43.97 \pm 0.27$ \\
\hline 240 & 6.8 & $50.57 \pm 0.39$ & $59.59 \pm 0.51$ \\
\hline 300 & 6.8 & $56.19 \pm 0.61$ & $70.98 \pm 0.38$ \\
\hline 360 & 6.8 & $65.27 \pm 0.27$ & $71.87 \pm 0.42$ \\
\hline 375 & 7.4 & $77.75 \pm 0.38$ & $79.50 \pm 0.67$ \\
\hline 390 & 7.4 & $81.18 \pm 0.47$ & $88.37 \pm 0.75$ \\
\hline 420 & 7.4 & $89.65 \pm 0.42$ & $98.61 \pm 0.23$ \\
\hline 450 & 7.4 & $99.50 \pm 0.31$ & $100.000 \pm 0.46$ \\
\hline 480 & 7.4 & $100.000 \pm 0.53$ & \\
\hline
\end{tabular}




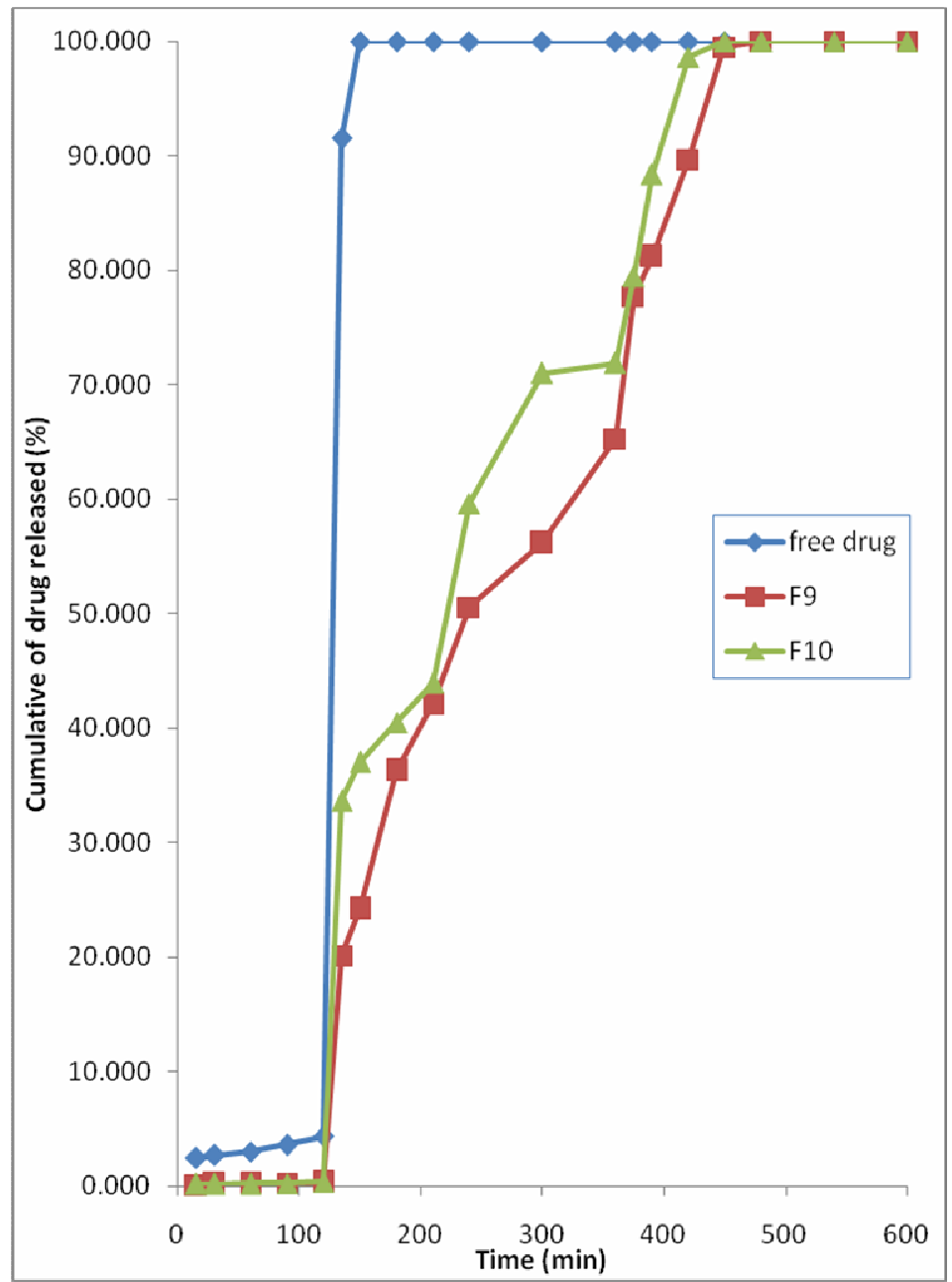

Fig. 4: Cumulative release of Diflunisal results from Diflunisal : Eudragit S100 solid : Ethylcellulose solid dispersions and the free drug at various $\mathrm{pH}$ values.

The release results of the solid dispersions F11, F12, F13, F14 and F15 which contain $1: 3: 2,1: 1: 1,1: 1: 2,1: 0.5: 1.5$ and $1: 1: 1.5$ drug to Eudragit S100 to Eudragit RS100 ratio respectively are illustrated in table 7 and figure 5. These results indicate that at $\mathrm{pH} 1.2$, the $\%$ of the amounts of the drug released were $0.217 \pm 0.03,0.29 \pm 0.00,0.20 \pm 0.03,0.27 \pm 0.01$ and $0.32 \pm 00.03 \%$ from F11, F12, F13, F14, and $\mathrm{F} 15$ respectively. The release efficiencies (\%DE) of F11, F12, F13, F14 and F15 solid dispersions were $0.14 \pm 0.09, \quad 0.18 \pm 0.04$, $0.18 \pm 0.04, \quad 0.17 \pm 0.06$ and $0.22 \pm 0.11 \%$ respectively.

At $\mathrm{pH} 6.8$ the \% of the amounts of the drug released after $240 \mathrm{~min}$ were $26.29 \pm 0.91$, $60.52 \pm 0.67, \quad 22.59 \pm 0.38, \quad 50.36 \pm 0.46$ and $71.72 \pm 0.62 \%$ from F11, F12, F13, F14, and $\mathrm{F} 15$, respectively. At this $\mathrm{pH}$ value, all combined $\mathrm{pH}-$ and time-dependent solid dispersion provided a significant reduction in the cumulative percentage released after 240 min. The release efficiencies (\%DE) of F11, F12, F13, F14 and F15 solid dispersions were $17.47 \pm 0.23, \quad 49.36 \pm 0.19, \quad 17.46 \pm 0.35$, $41.26 \pm 0.22$ and $62.66 \pm 0.38 \%$ respectively.

At $\mathrm{pH} 7.4$ the \% of the amounts of the drug released after 240 min were $77.59 \pm 1.79$, $100.00 \pm 0.71, \quad 30.97 \pm 0.31, \quad 80.77 \pm 0.44$ and $100.00 \pm 0.54 \%$ from F11, F12, F13, F14, and F15, respectively. The release efficiencies (\%DE) of F11, F12, F13, F14 and F15 solid dispersions were $60.73 \pm 0.09, \quad 80.49 \pm 0.16$, $27.34 \pm 0.11, \quad 65.75 \pm 0.24$ and $87.16 \pm 0.10 \%$ respectively.

It is clear that the addition of time dependent polymer in combined $\mathrm{pH}$ - and time- 
dependent system could control drug release at $\mathrm{pH} 7.4$ and as a result, the delivery of much more drug to the colon would be guaranteed as compared to $\mathrm{pH}$-dependent system (Akhgari et $a l .^{33}$.
From the obtained results, it could be concluded that F11 and F14 showed good results as colonic drug delivery systems but $\mathrm{F} 11$ is better than F14 as it protect about $75 \%$ of the from being released in the intestine. F14 protect only $50 \%$ of the drug until it reaches the colon.

Table 7: Cumulative Diflunisal released from Diflunisal : Eudragit S100 : Eudragit RS100 solid dispersions at various $\mathrm{pH}$ values.

\begin{tabular}{|c|c|c|c|c|c|c||}
\hline \multirow{2}{*}{$\begin{array}{c}\text { Time } \\
\text { (min) }\end{array}$} & \multirow{2}{*}{$\mathrm{pH}$} & \multicolumn{5}{|c|}{ Cumulative amount of Diflunisal (\%) \pm S.D. } \\
\cline { 3 - 7 } & & $\mathrm{F} 11$ & $\mathrm{~F} 12$ & $\mathrm{~F} 13$ & F14 & F15 \\
\cline { 3 - 7 } & & $1: 3: 2$ & $1: 1: 1$ & $1: 1: 2$ & $1: 0.5: 1.5$ & $1: 1: 1.5$ \\
\hline 15 & 1.2 & $0.06 \pm 0.01$ & $0.11 \pm 0.01$ & $0.05 \pm 0.01$ & $0.09 \pm 0.01$ & $0.14 \pm 0.03$ \\
\hline 30 & 1.2 & $0.11 \pm 0.04$ & $0.14 \pm 0.02$ & $0.09 \pm 0.05$ & $0.13 \pm 0.01$ & $0.18 \pm 0.01$ \\
\hline 60 & 1.2 & $0.11 \pm 0.02$ & $0.15 \pm 0.01$ & $0.10 \pm 0.02$ & $0.15 \pm 0.03$ & $0.21 \pm 0.05$ \\
\hline 90 & 1.2 & $0.17 \pm 0.07$ & $0.22 \pm 0.03$ & $0.16 \pm 0.02$ & $0.22 \pm 0.06$ & $0.25 \pm 0.02$ \\
\hline 120 & 1.2 & $0.22 \pm 0.03$ & $0.29 \pm 0.00$ & $0.20 \pm 0.03$ & $0.27 \pm 0.01$ & $0.32 \pm 00.03$ \\
\hline 135 & 6.8 & $1.29 \pm 0.12$ & $19.28 \pm 0.13$ & $10.34 \pm 0.13$ & $26.54 \pm 0.21$ & $43.76 \pm 0.12$ \\
\hline 150 & 6.8 & $9.48 \pm 0.44$ & $31.43 \pm 0.64$ & $11.50 \pm 0.25$ & $30.23 \pm 0.19$ & $49.72 \pm 0.23$ \\
\hline 180 & 6.8 & $13.21 \pm 0.23$ & $42.83 \pm 0.25$ & $14.25 \pm 0.15$ & $33.66 \pm 0.28$ & $54.89 \pm 0.38$ \\
\hline 210 & 6.8 & $15.64 \pm 0.68$ & $47.91 \pm 0.78$ & $16.91 \pm 0.41$ & $38.06 \pm 0.12$ & $60.59 \pm 0.26$ \\
\hline 240 & 6.8 & $17.76 \pm 0.73$ & $54.97 \pm 0.51$ & $18.14 \pm 0.17$ & $43.24 \pm 0.17$ & $65.25 \pm 0.51$ \\
\hline 300 & 6.8 & $22.95 \pm 0.52$ & $57.80 \pm 0.34$ & $20.28 \pm 0.22$ & $48.42 \pm 0.34$ & $70.68 \pm 0.33$ \\
\hline 360 & 6.8 & $26.29 \pm 0.91$ & $60.52 \pm 0.67$ & $22.59 \pm 0.38$ & $50.36 \pm 0.46$ & $71.72 \pm 0.62$ \\
\hline 375 & 7.4 & $33.73 \pm 1.07$ & $63.98 \pm 0.41$ & $24.03 \pm 0.14$ & $53.49 \pm 0.27$ & $75.08 \pm 0.28$ \\
\hline 390 & 7.4 & $40.37 \pm 0.84$ & $65.33 \pm 0.27$ & $24.82 \pm 0.27$ & $55.88 \pm 0.22$ & $77.06 \pm 0.31$ \\
\hline 420 & 7.4 & $45.87 \pm 1.29$ & $68.39 \pm 0.64$ & $25.66 \pm 0.16$ & $58.26 \pm 0.41$ & $79.98 \pm 0.44$ \\
\hline 450 & 7.4 & $54.71 \pm 1.36$ & $75.59 \pm 0.82$ & $26.51 \pm 0.23$ & $60.38 \pm 0.34$ & $83.95 \pm 0.82$ \\
\hline 480 & 7.4 & $67.22 \pm 1.24$ & $79.66 \pm 0.73$ & $27.09 \pm 0.19$ & $63.56 \pm 0.23$ & $87.92 \pm 0.98$ \\
\hline 540 & 7.4 & $72.25 \pm 1.62$ & $89.69 \pm 0.95$ & $28.74 \pm 0.22$ & $73.09 \pm 0.53$ & $92.16 \pm 0.72$ \\
\hline 600 & 7.4 & $77.59 \pm 1.79$ & $100.00 \pm 0.71$ & $30.97 \pm 0.31$ & $80.77 \pm 0.44$ & $100.00 \pm 0.54$ \\
\hline \hline
\end{tabular}




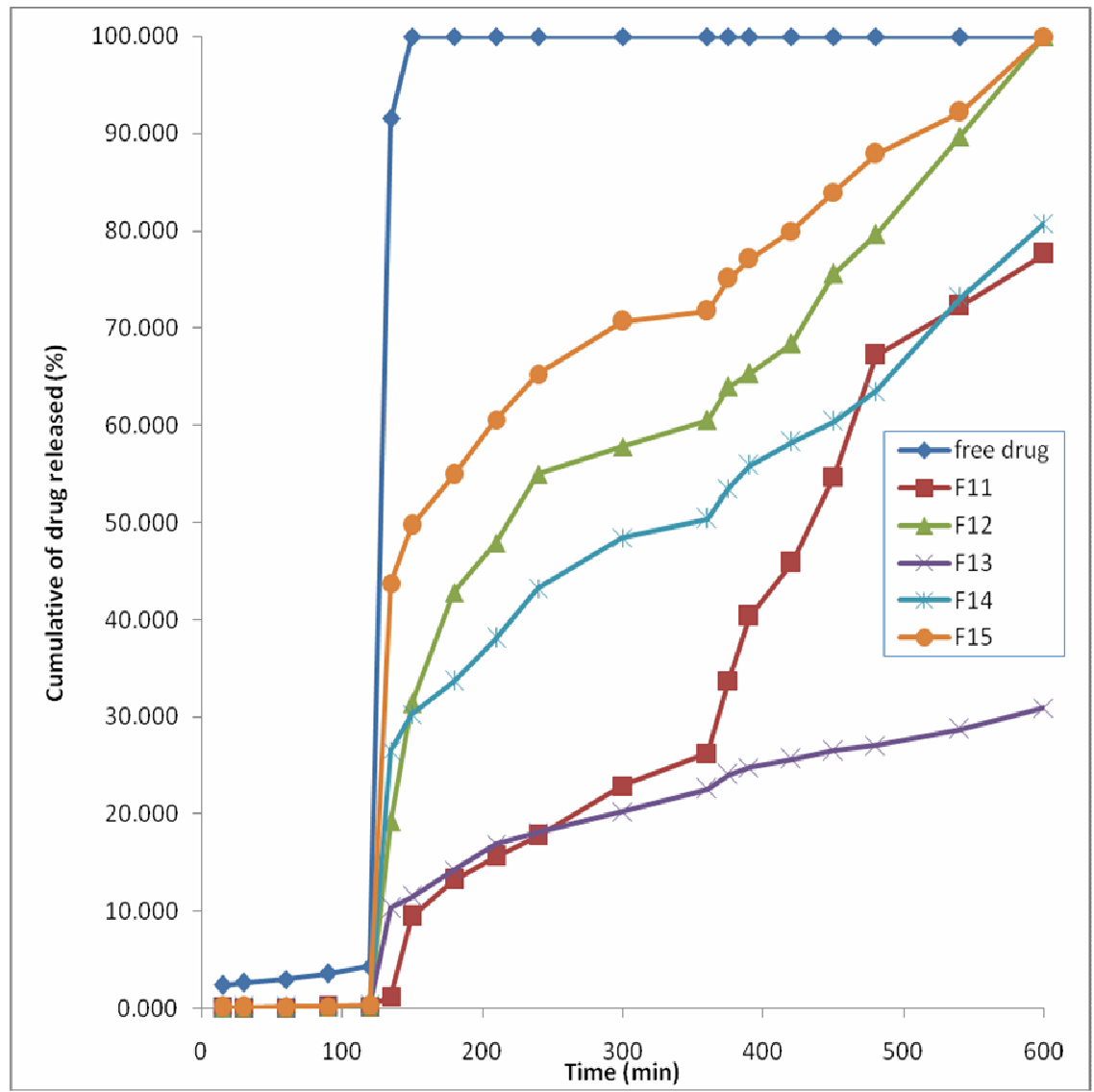

Fig. 5: Cumulative release results of Diflunisal from Diflunisal : Eudragit S100 : Eudragit RS100 solid dispersions and the free drug at various $\mathrm{pH}$ values.

\section{REFERENCE}

1- N. X. Wang and H. A. Recum, "Affinitybased drug delivery", Macromol Biosci, 11 (3), 321-332 (2011). doi: 10.1002/mabi. 201000206 .

2- N. Bertrand and J. C. Leroux, "The journey of a drug carrier in the body: An anatomo-physiological perspective", $\boldsymbol{J}$. Cont. Rel., 161 (2), 152-163 (2012). doi:10.1016/j.jconrel. 2011.09.098 .

3- A. Patel, N. Bhatt, K. R. Patel, N. M. Patel and M. R. Patel, "Colon targeted drug delivery system: A review system" $\boldsymbol{J}$. Pharm. Sci. and Bios. Research, 1 (1), 37-49 (2011).

4- A. Patel, N. Bhatt, K. R. Patel and S. Shah, "Colon targeted drug delivery system: A review system", College of Pharm. Edu. \& Research Journal, Modasa-383315, Gujarat, India (2001).
5- T. F. Dolan, M. J. Humphrey, D. J. Nichols, A. K. Philip, R. K. Dubey and K. Pathak, "Optimizing delivery of furbiprofen to the colon using a targeted prodrug approach", J. Pharm. Pharmacol., US20006106864 (2000), 60, 607-613 (2008).

6- G. T. Macfarlane and J. H.Cummings, "The Colonic Flora, Fermentation and Large Bowel Digestive Function", The Large Intenstine: Physiology, Pathophysiology and Disease, New York: Raven press, 1991, 45, pp. 22-29.

7- Y. S. Krishnaiah and S. Styanarayana, "Colon- Specific Drug Delivery Systems", In Jain NK, Advances in Controlled and Novel Drug Delivery, CBS Publishers and Distributors, New Delhi, 2000, 66, pp. $72-$ 81.

8- V. C. Ibekwe, H. M. Fadda, G. E. Parsons and A. W. Basit, "A comparative in-vitro assessment of the drug release 
performance of $\mathrm{pH}$-responsive polymers for ileo-colonic delivery", Int. J. Pharm., 308, 52-60 (2006).

9- M. Rangasamy, "Colon targeted drug delivery systems: A review", Int. J. Drug Formul. \& Res., 1 (11), 30-54 (2010).

10- V. D. Kadam and S. G. Gattani, "Formulation and evaluation of a pulsatile drug delivery system using time- and $\mathrm{pH}-$ dependent polymers", Pharm. Dev. Technol., 15 (1), 57-63 (2010).

11- R. P. Chan, D. J. Pope, A. P. Gilbert, P. J. Sacra, J. H. Baron and J. E. LennardJones, "Studies of two novel sulphasalazine analogs I.P. salazide and balsalazide", Digestive Diseases and Sciences, 28 (7), 609-615 (1983).

12- V. Jain and R. Singh, "Development and characterization of Eudragit ${ }^{\circledR}$ S100 loaded microsponges and its colonic delivery using natural polysaccharides", Acta Poloniae Pharmaceutica-Drug Research, 67 (4), 407-415 (2010).

13- A. Akhgari, F. Sadeghi and H. Garekani, "Combination of time dependent and $\mathrm{pH}$ dependent polymethacrylates as a single coating formulation for colonic delivery of indomethacin pellets", Int. J. Pharm., 320 (1-2), 137-142 (2006).

14- R. Serajuddun, "Solid dispersion technique", J. Pharm. Sci., 88, 891-900 (1999).

15- R. Alex and R. Bodmeier, "Encapsulation of water-soluble drugs by a modified solvent evaporation method. I. Effect of process and formulation variables on drug entrapment", J. Microencapsul., 7 (3), 347-355 (1990).

16- M. G. Vachon and J. G. Nairn, " Physicochemical evaluation of acetylsalicylic acid-Eudragit $^{\circledR} \quad$ RS100 microspheres prepared using a solvent-partition method", ibid., 12 (3), 287-305 (1995).

17- M. Morishita and N. A. Peppas, "Is the oral route possible for peptide and protein drug delivery?" Drug Discovery Today, 11 (19-20), 905-910 (2006).

18- T. Oosegi, H. Onishi and Y. Machida, "Novel preparation of enteric-coated chitosan-prednisolone conjugate microspheres and in-vitro evaluation of their potential as a colonic delivery system", Eur. J. Pharm. and Biopharm., 68 (2), 260-266 (2008).

19- R. I. Moustafine, I. M. Zaharov and V. A. Kemenova, "Physicochemical characterization and drug release properties of Eudragit $^{\circledR} \quad$ E $\quad$ PO/Eudragit ${ }^{\circledR}$ L $\quad 100-55$ interpolyelectrolyte complexes", ibid., 63(1), 26-36 (2006).

20- S. Haznedar and A. Dortunç, "Preparation and in-vitro evaluation of Eudragit microspheres containing acetazolamide", Int. J. Pharm., 269 (1), 131-140 (2004).

21- F. Dourado, M. Bastos, M. Mota and F. M. Gama, "Studies on the properties of Celluclast/Eudragit L-100 conjugate", $\boldsymbol{J}$. Biotech., 99 (2), 121-131 (2002).

22- Y. Krishnamachari, P. Madan and S. Lin, "Development of $\mathrm{pH}$ - and time-dependent oral microparticles to optimize budesonide delivery to ileum and colon", Int. J. Pharm., 338 (1-2), 238-247 (2007).

23- E. Allémann, J. Leroux and R. Gurny, "Polymeric nano- and microparticles for the oral delivery of peptides and peptidomimetics", Adv. Drug Deliv. Rev., 34, 171-189 (1998).

24- M. Zahirul, I. Khan , H. P. Stedul and N. Kurjaković, "A pH-dependent colontargeted oral drug delivery system using methacrylic acid copolymers. II. manipulation of drug release using Eudragit ${ }^{\circledR}$ L100 and Eudragit S100 Combinations", J. Cont. Rel., 58, 549-54 (1991).

25- L. Asghar and S. Chandran, "Design and evaluation of $\mathrm{pH}$ modulated controlled release matrix systems for colon specific delivery of indomethacin", Die Pharmazie., 63, 736-742 (2008).

26- L. F. A. Asghar, C. B. Chure and S. Chandran, "Colon specific delivery of' indomethacin: effect of incorporating $\mathrm{pH}$ sensitive polymers in xanthan gum matrix bases", AAPS Pharm. Sci. Tech., 10 (2), 418-429 (2009).

27- R. Pignatello, D. Amico, S. Chiechio, P. Giunchedi, C. Spadaro and G. Puglisi, "Preparation and analgesic activity of Eudragit RS100 microparticles containing diflunisal drug deliv.", Drug Deliv., 8 (1), 35-45 (2001).

28- R. Pignatello, M. Ferro, G. Guidi, G. Salemi, M. Vandelli, S. Guccione, M. 
Geppi, C. Forte and G. Puglisi, "Preparation, characterisation and photosensitivity studies of solid dispersions of Diflunisal and Eudragit $\mathrm{RS}_{100}{ }^{\circledR}$ and $\mathrm{RL} 100^{\circledR}$, Int. J. Pharm., 218, 27-42 (2001).

29- M. Z. I. Khan, Z. Prebeg and N. Kurjaković, "A pH-dependent colon targeted oral drug delivery system using methacrylic acid copolymers. I. Manipulation of drug release using Eudragit $^{\circledR}$ L100-55 and Eudragit ${ }^{\circledR}$ S100 combinations", J. Cont. Rel., 58, 215-222 (1999).

30- V. D. Kadam and S. G. Gattani, "Formulation and evaluation of a pulsatile drug delivery system using time- and $\mathrm{pH}-$ dependent polymers", Pharm. Dev. Technol., 15 (1), 57-63 (2010).
31- S. Benita and M. Donbrow, "Controlled drug delivery through microencapsulations", J. Pharm. Sci., 71, 205210 (1982).

32- K. Gowda, M. P. Gowrav, H. V.Gangadharappa and M. S. Khan, "Preparation and evaluation of mixture of Eudragit S100 and ethylcellulose microparticles loaded with ranolazine for controlled release", J. of Young Pharm. JYP, 3, 189-196 (2011).

33- A. Akhgari, F. Sadeghi and H. A. Garekani, "Combination of $\mathrm{pH}$-dependent and time-dependent polymers as a single coating for design of colon delivery system of indomethacin", Int. J. Pharm., 320 (1-2), 137-142 (2006). 


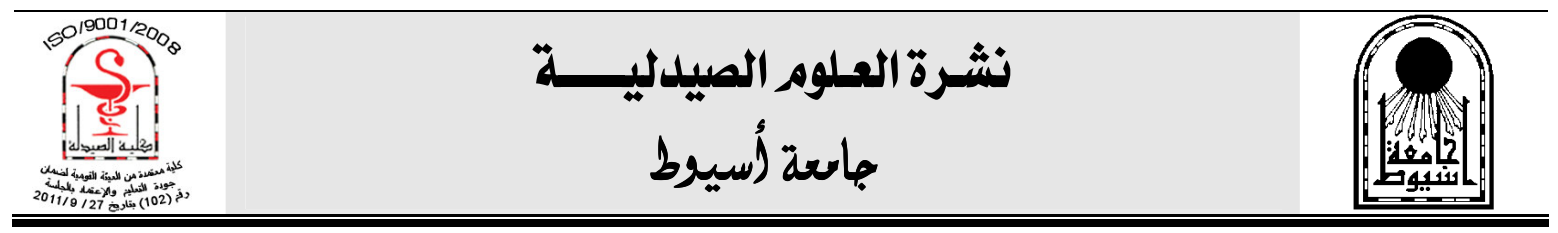

\section{صياغة وتقييم أنظمة دوائية للإنطلاق إلي القولون تحتوي علي عقار دفلونيزال}

عصمت زين الدين - جمال المغربى - أحمد دنيا - سمر مياح

\section{قسم التكنولوجيا الصيدلية ، كلية الصيدلة ، جامعة طنطا ، مصر}

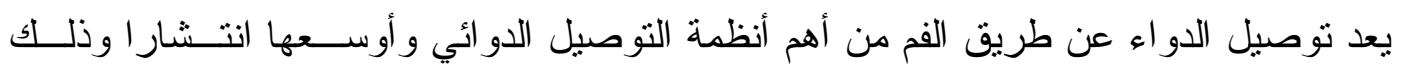

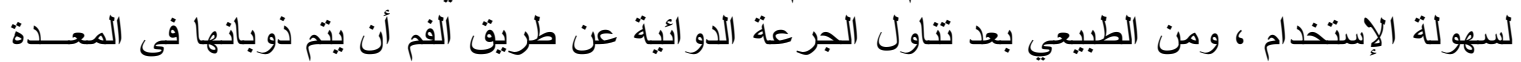

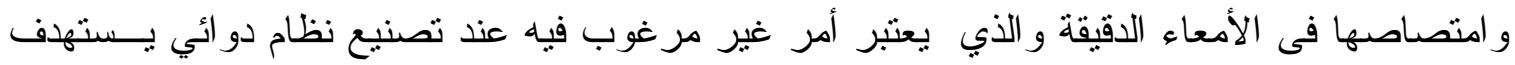

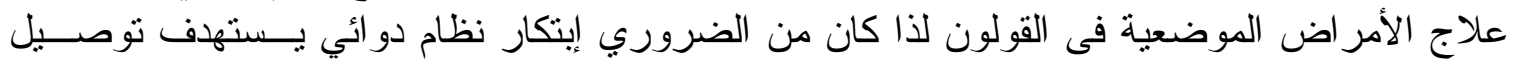

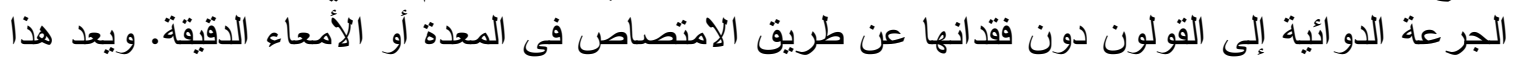

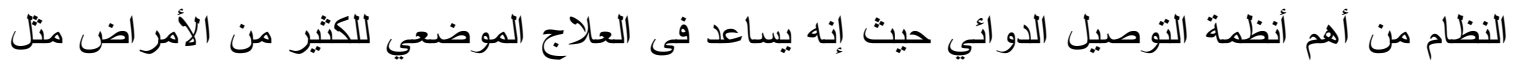

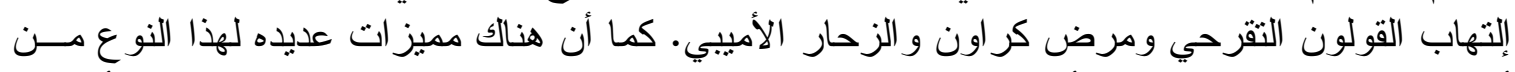

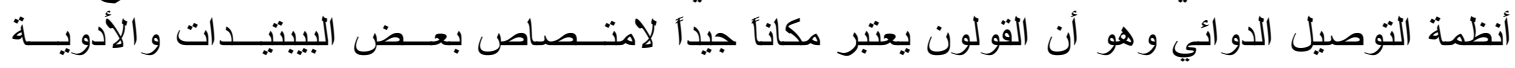

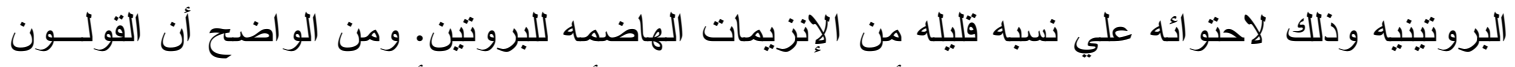

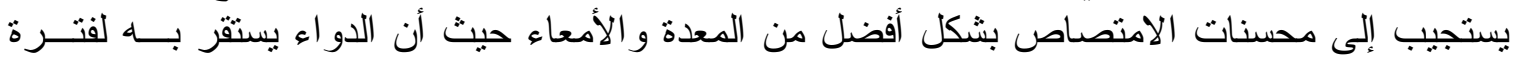

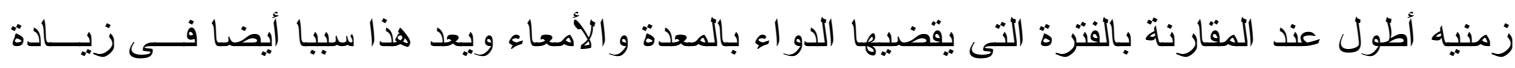

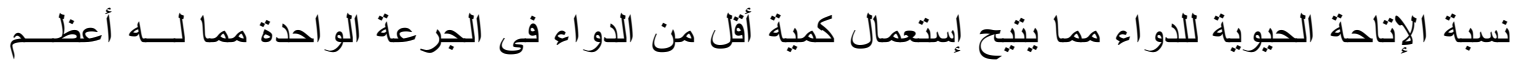

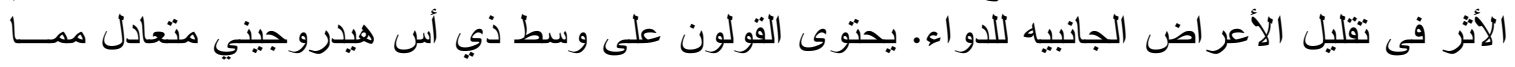

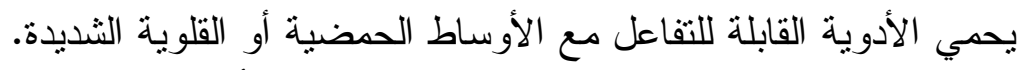

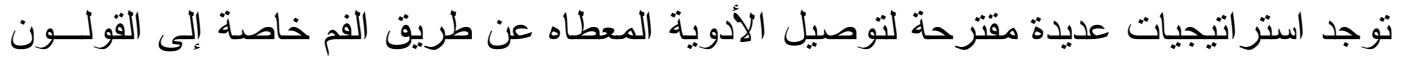

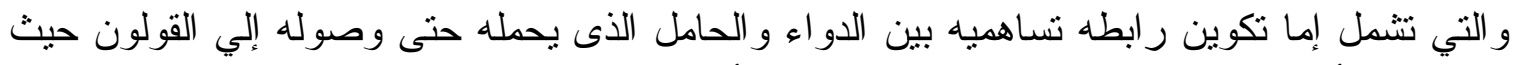

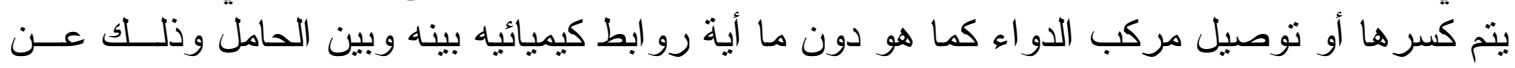

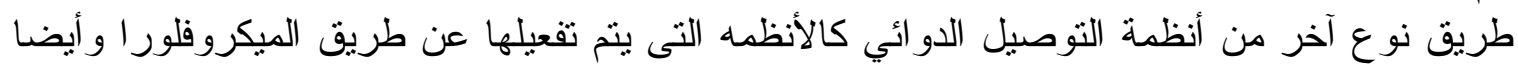

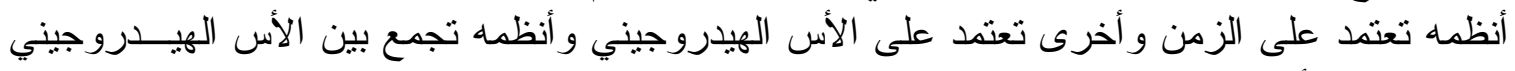

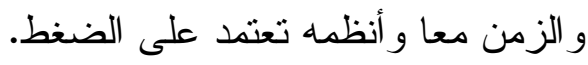

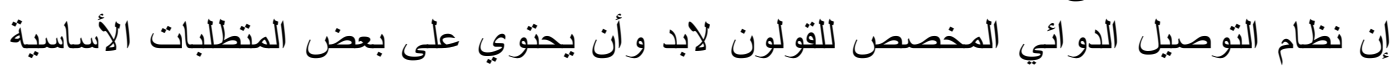

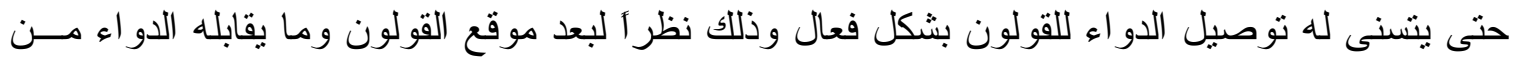

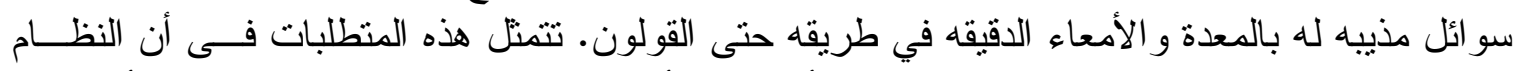

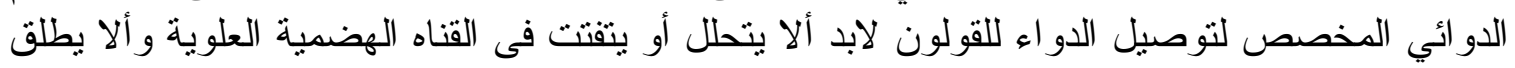

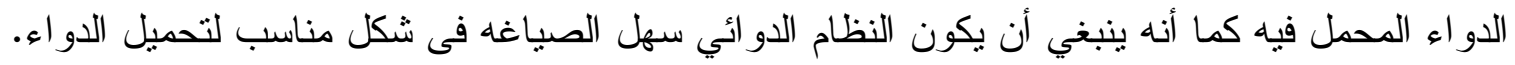

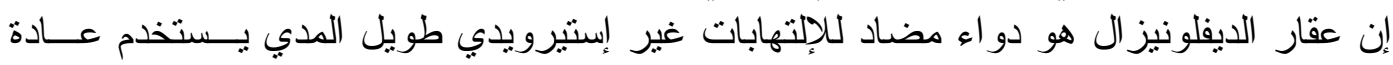

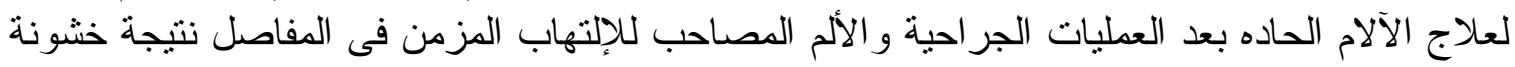

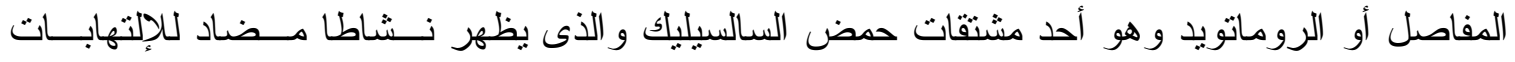

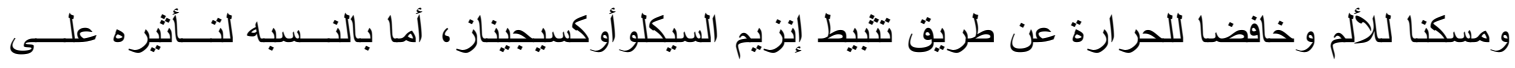




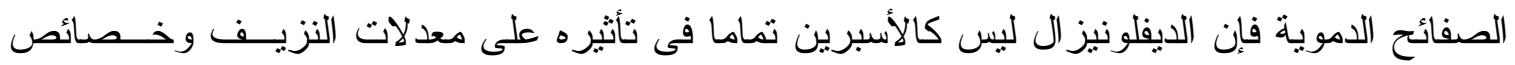

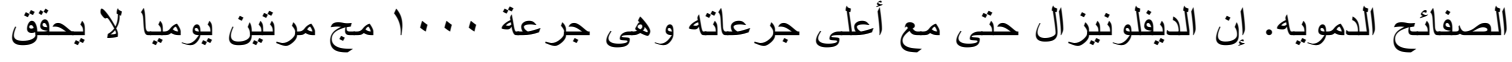

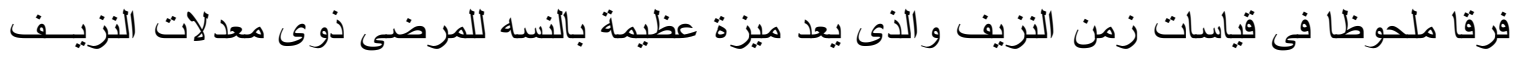

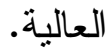

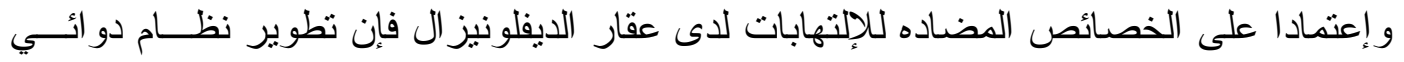

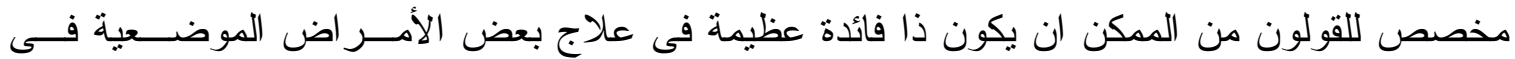

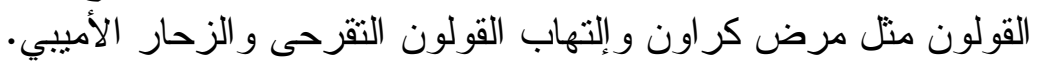

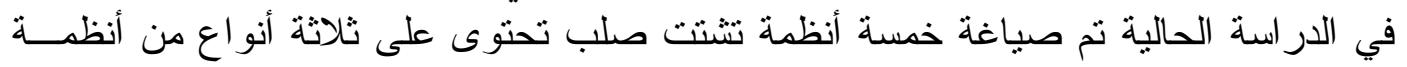

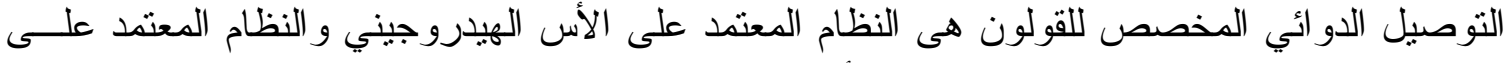

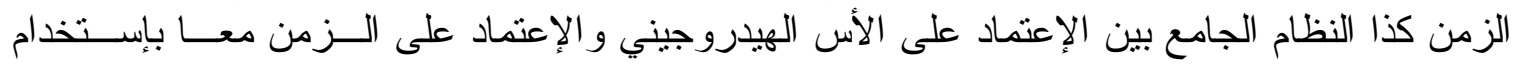

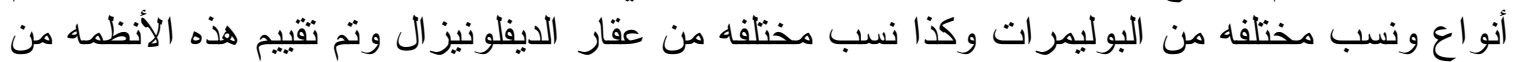

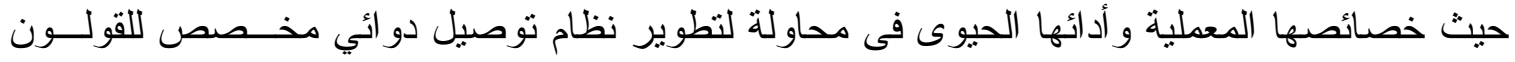

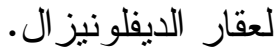

